\title{
Validation of the CoaguChek XS international normalised ratio point-of-care analyser in patients at Charlotte Maxeke Johannesburg Academic Hospital, South Africa
}

\author{
E L Benade, MB BCh; B F Jacobson, MB ChB, MMed (Haem), FRCS (Glasg), FCPath (SA), PhD (Med); \\ S Louw, MB BCh, FCPath (SA), MMed (Haem); E Schapkaitz, MB BCh, FCPath (SA), MMed (Haem)
}

National Health Laboratory Service, Johannesburg, South Africa, and Department of Haematology, Faculty of Health Sciences, University of the Witwatersrand, Johannesburg

Corresponding author: E Benade (estee.benade@nhls.ac.za)

\begin{abstract}
Background. Measurement of the international normalised ratio (INR) is essential in the management of patients on long-term warfarin therapy. The CoaguChek XS portable coagulometer is a point-of-care test for INR measurement. It offers the advantage of improved patient accessibility, particularly in peripheral clinics.

Objectives. To evaluate the clinical utility of the CoaguChek XS for monitoring of patients on standard warfarin therapy (INR 2 - 3) as well as those with mechanical heart valve replacements (INR 2.5 - 3.5).

Methods. We compared the performance of the CoaguChek XS device with that of the STAGO laboratory analyser with regard to accuracy and precision in 304 patients referred for routine testing.

Results. The mean INR value of the CoaguChek XS of 2.75 (standard deviation (SD) 1.18) was comparable to that of the STAGO (2.65 (SD 1.04)). The Bland-Altman difference plot revealed good agreement. Bias between the two methods was small, and the imprecision was within acceptable limits. Within the target range (2.0 - 3.5), 93.9\% of the CoaguChek XS INR readings were within 0.5 units of the standard laboratory method result. There was, however, an increase in the variability of the differences between the two test methods when the INR was $>3.6$.

Conclusion. The CoaguChek XS point-of-care device can be used to provide accurate and precise INR measurements over a wide range for monitoring of valvular and non-valvular patients on long-term warfarin therapy.
\end{abstract}

S Afr Med J 2016;106(3):280-283. DOI:10.7196/SAMJ.2016.v106i3.9422

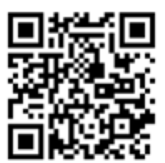

Point-of-care testing (POCT) is the fastest-growing segment of the diagnostic tests used by laboratories in the developed world. Laboratories have become increasingly involved in supporting testing at the bedside in order to improve turnaround time and reduce the cost of healthcare delivery.

Measurement of the international normalised ratio (INR) is essential in the management of patients on long-term warfarin therapy, and POCT has an important role to play in this setting. Warfarin has a narrow therapeutic range, and because it is subject to numerous drug and food interactions, frequent monitoring to maintain the target INR is vital. The target INR is 2.5 (range 2.0 3.0) for most indications, including venous thromboembolic disease, non-valvular cardiac conditions including atrial fibrillation, left ventricular systolic dysfunction and mural thrombus, and in the first 3 months following anterior myocardial infarction. The target INR is 3.0 (range 2.5 - 3.5) for most patients with mechanical prosthetic valves. However, a range of $2.0-3.0$ is recommended for low-risk patients with bileaflet mechanical valves in the aortic position.

Predisposing factors for rheumatic fever persist in developing areas of southern Africa, leading to a high incidence of rheumatic valvular heart disease. An average of 1500 patients attend the anticoagulation clinic at Charlotte Maxeke Johannesburg Academic Hospital (CMJAH), South Africa (SA), every month. Twenty-five percent of these are patients with mechanical valve replacements on lifelong anticoagulation therapy. In the developing world the question still remains whether it is safe to perform mechanical valve replacements in patients who will require lifelong anticoagulation therapy and have limited or no access to its monitoring. The introduction of POCT in peripheral clinics has the potential to solve this problem. There is also an opportunity for self-monitoring for patients who are able to test themselves at home and avoid taking time off from work to attend a clinic for INR testing.

POCT offers other distinct advantages, including improved turnaround time for dose adjustments in the clinic setting, a small sample volume required for testing and potential long-term cost savings. The volume required for analysis is very small $(8 \mu \mathrm{L})$, making this technology particularly suitable for paediatric measurements, as blood sampling in this age group is often technically difficult.

Many POC devices are commercially available. The CoaguChek XS device (Roche Diagnostics, Switzerland) is a small bench-top instrument for INR analysis, suitable for use in anticoagulation clinics. This analyser measures the prothrombin time (PT) in seconds using an electrochemical method and shows good correlation with laboratory automated coagulation analysers up to INR values of 3.0. ${ }^{[1,2]}$ However, correlation studies at INR values $>3.0$ are limited. ${ }^{[3-6]}$

\section{Methods}

Study design and population

The study was performed in the main haematology laboratory at the CMJAH National Health Laboratory Service (NHLS) over a 3-week period. Blood samples were obtained from 304 patients attending the anticoagulation clinic at CMJAH. Blood samples for INR analysis were obtained by fingerstick testing for measurement on the CoaguChek $\mathrm{XS}$ and by venepuncture using citrate tubes (Becton-Dickinson, UK) for measurement on the STAGO coagulation analysers in 
the laboratory (Fig. 1). Citrate samples of adequate volume $(>4 \mathrm{~mL})$ received within 2 hours of collection were included. Samples $(n=4)$ processed on the CoaguChek that yielded error results were excluded from the final analysis.

The study was approved by the University of the Witwatersrand Human Research Ethics Committee (M130468), and informed consent was obtained from the patients.

\section{Study protocol}

This validation was performed in accordance with the International Council for Standardisation in Hematology 1993, and using the method comparison from the Clinical and Laboratory Standards Institute (CLSI EP9-A2, USA). For the method comparison study, a prospective, side-byside comparative study of the CoaguChek XS against the STAGO (Roche Diagnostics, Switzerland) automated coagulation analyser was performed. INR measurement was done on 304 adult patient samples. The samples were analysed sequentially by a dedicated phlebotomist on the CoaguChek XS and by a technologist on the STAGO coagulation analyser using the respective instruments' standard operating procedures including adequate performance of internal quality control material (Fig. 1).

For the analysis, whole blood collected by capillary sampling was placed on a CoaguChek XS specific test strip. The strips contain recombinant human thromboplastin with an international sensitivity index (ISI) of 1.0. The PT was converted to an INR using the ISI value. A result is obtained within a minute and requires a sample volume of only $8 \mu \mathrm{L}$.

Within-run precision evaluation was performed with the normal reference control material analysed 20 times. Acceptable imprecision limits were determined from the manufacturer's within-run precision data.

\section{Warfarin dosage and INR measurements}

Clinical utility was assessed by two methods. Firstly, clinical agreement was measured by discrepant INR measurements resulting in different warfarin dosage adjustments in accordance with the SA guidelines. ${ }^{[7]}$ Warfarin dosage adjustments were made by dedicated nursing sisters at the anticoagulation clinic based on the venous plasma laboratory INR method.

Secondly, published criteria for 'expanded' and 'narrow' clinical agreement were also assessed. ${ }^{[2]}$ 'Expanded' agreement was achieved if the CoaguChek XS and laboratory INR results both fell within one of the three different INR ranges, namely

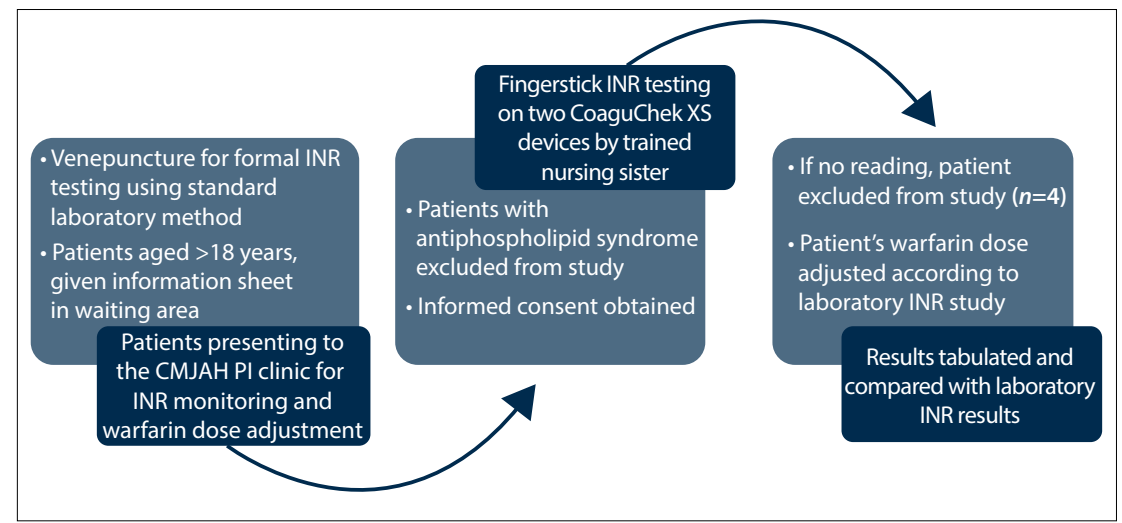

Fig. 1. Flow diagram of patient sample collection. (PI clinic=anticoagulation clinic.)

within, above or below the target range, or the difference between the CoaguChek XS and laboratory INR when one of the pair was within the target range and the other outside it was no more than 0.5 INR units.

'Narrow' agreement was considered as both readings being between 2 and 3 , or below the target range and within 0.4 INR units of each other, or above the target range and within 0.8 INR units of each other. If one reading was within the target range and the other within 0.5 INR units, this was also considered to be in 'narrow' agreement. ${ }^{[1,5]}$

\section{Statistical analysis}

The results were collated on an Excel spreadsheet, tabulated and graphically summarised using standard statistical methods. Agreement between results obtained on the different analysers was evaluated using standard difference plots.

\section{Results \\ Study population}

Three hundred and four patients participated in the study. In four cases the CoaguChek XS device failed to produce an INR reading, and these samples were excluded from the analysis (Fig. 1). Patient indications for anticoagulation are listed in Table 1.

\section{Method comparison analysis}

The limit of agreement between the two methods is demonstrated in the BlandAltman difference plot (Fig. 2), which revealed good agreement. On the logarithmic scale, the mean of the differences was $0.09(-0.61,0.79)$. Sixteen data points were outside the $95 \%$ limits of agreement. The mean INR values of the CoaguChek XS and STAGO were 2.75 (standard deviation (SD) 1.18) and 2.65 (SD 1.04), respectively, representing an overestimation of INR values by the CoaguChek XS (Table 2). Below the target range $(<1.9), 100 \%$ of the CoaguChek XS INR readings were within 0.5 units of the

\begin{tabular}{ll}
$\begin{array}{l}\text { Table 1. Indications for anticoagulation } \\
\text { of study patients }\end{array}$ \\
\hline $\begin{array}{l}\text { Indication for } \\
\text { anticoagulation }\end{array}$ & $\boldsymbol{n}(\%)$ \\
\hline Thromboembolic events & $110(36.2)$ \\
\multicolumn{1}{|c}{ Deep-vein thrombosis } & $54(17.8)$ \\
Pulmonary embolism & $32(10.5)$ \\
Deep-vein thrombosis and & $13(4.3)$ \\
pulmonary embolism & \\
Upper limb thrombosis & $5(1.6)$ \\
Left ventricular thrombus & $5(1.6)$ \\
Dural venous sinus & $1(0.3)$ \\
thrombosis & \\
Valvular heart disease & $59(19.4)$ \\
Non-valvular heart disease & $87(28.6)$ \\
Dilated cardiomyopathy & $5(1.6)$ \\
Congestive cardiac failure & $4(1.3)$ \\
Ischaemic heart disease & $4(1.3)$ \\
Stroke & $3(0.9)$ \\
Congenital cardiac disease & $2(0.7)$ \\
Atrial fibrillation & $69(22.7)$ \\
Other/not stated & $48(15.8)$ \\
&
\end{tabular}

standard laboratory method result. Within the target range $(2.0-3.5), 93.9 \%$ of the CoaguChek XS INR readings were within 0.5 units of the standard laboratory method result. There was, however, an increase in the variability of the differences between the two test methods at INR readings above the target range (>3.6).

\section{Precision analysis}

The intra-assay coefficients of variation were within allowable limits of performance in the within-target range (0\%).

\section{Clinical utility}

Clinical agreement was demonstrated by $93.0 \%$ of the values when assessed using 


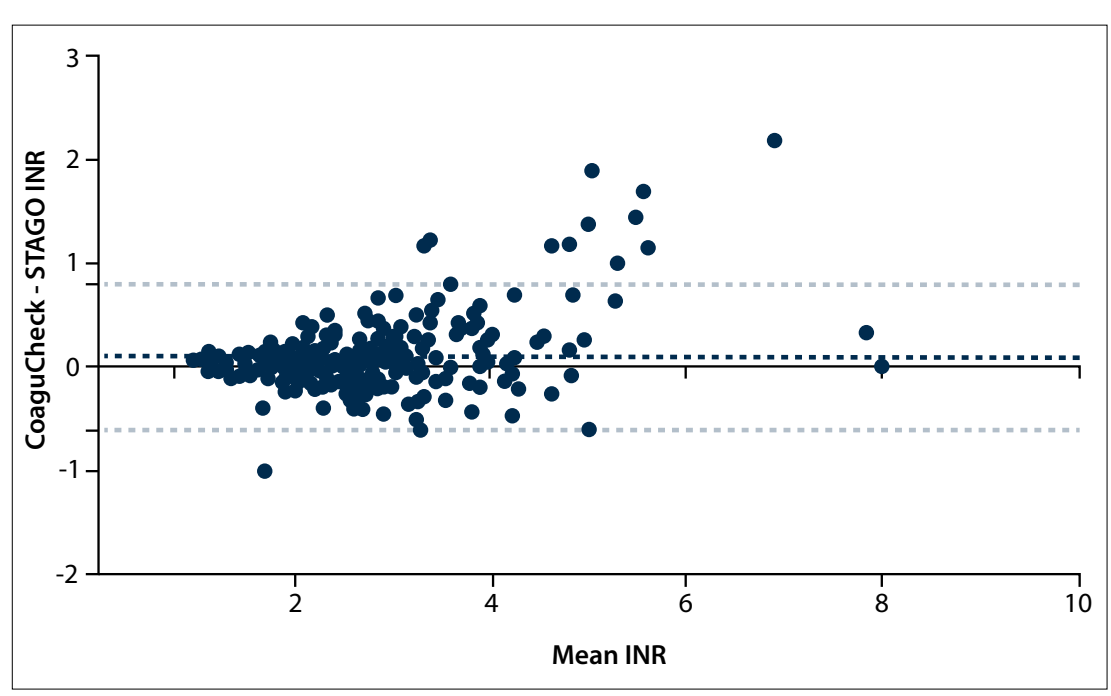

Fig. 2. Bland-Altman analysis. (95\% confidence intervals in blue, bias indicated in black. The dots indicate the difference between the CoaguChek and STAGO INR over the mean.)

\begin{tabular}{lll}
\multicolumn{4}{l}{ Table 2. Comparison of CoaguChek XS and laboratory INR results } & \\
\hline Parameter & CoaguChek XS & Laboratory \\
\hline All INR results, $N$ (\%) & $300(100.0)$ & \\
Mean INR (SD) & $2.75(1.18)$ & $2.65(1.04)$ \\
Mean difference (SD) & $-0.09(0.36)$ & \\
\% within 0.5 units & 93.0 & \\
INR $\leq 1.9, n$ (\%) & $71(23.7)$ & \\
Mean INR (SD) & $1.61(0.32)$ & $1.59(0.30)$ \\
Mean difference (SD) & $-0.03(0.11)$ & \\
$\%$ within 0.5 units & 100.0 & \\
INR 2.0 - 3.5, $n$ (\%) & $184(61.3)$ & \\
Mean INR (SD) & $2.66(0.50)$ & $2.61(0.39)$ \\
Mean difference (SD) & $-0.05(0.28)$ & \\
$\%$ within 0.5 INR units & 93.9 & \\
INR $\geq 3.6, n$ (\%) & $45(15.0)$ & \\
Mean INR (SD) & $4.9(1.3)$ & \\
Mean difference (SD) & $-0.3(0.7)$ & \\
$\%$ within 0.5 INR units & 64.4 & \\
\end{tabular}

expanded criteria. When using narrow agreement criteria, in the range of $2-3.5$, the laboratory method recorded 181 readings, whereas the CoaguChek XS device recorded $162(89.5 \%)$. At INR values $<2$, the difference between the two readings was $<0.4$ units in 70 of the 71 readings $(98.6 \%)$. The required difference of $<0.8$ units in the INR $>3.5$ category was met in 36 of the 45 readings (80.0\%) (Table 2).

During the study period, 21 of the 300 CoaguChek XS INR values (7.0\%) would have been discrepant with standard laboratory INR measurements, resulting in different warfarin dosage adjustments according to the SA guidelines. ${ }^{[7,8]}$

\section{Discussion}

In this prospective study, we demonstrated the analytical and clinical performance of the CoaguChek XS point-of-care device for the monitoring of warfarin therapy across a wide range of INR values. The CoaguChek $\mathrm{XS}$ is a portable coagulometer that was introduced into the clinical setting in October 2005. Previous studies on point-ofcare devices have shown increased variability at supratherapeutic INR levels. ${ }^{[2,9,10]}$ A recent study performed on the CoaguChek XS, however, demonstrated improved accuracy even at higher INR values. ${ }^{[11]}$

We demonstrated excellent agreement between the CoaguChek XS and laboratory measurement with the STAGO analyser. INR values were overestimated on the coagulometer. Ninety-four percent of the values had a clinically significant difference of $<0.5$ units in the target range, making this an acceptable alternative method for monitoring stable patients on long-term warfarin therapy with INRs within the therapeutic range of $2-3$. Using narrow agreement criteria, the point-of-care device also performed well in the INR ranges of $<2$ and $2-3.5$. However, in the above-target range of $>3.6,64.4 \%$ were in agreement. These findings are consistent with the study by Ryan et al., ${ }^{[12]}$ in which 162 patients had dual measurements performed using the CoaguChek XS and standard laboratory methods. For laboratory INR values of $<1.9$, $2-3.5$ and $>3.6,97.8 \%, 89.3 \%$ and $67 \%$ of readings, respectively, were within 0.5 INR units. In the SA setting, where there is a high prevalence of rheumatic heart disease and patients with mechanical heart valves, the CoaguChek XS point-of-care device could be implemented as a method for monitoring these patients, but clinical correlation would be advised at levels $>3.6$ units with more frequent monitoring and formal laboratory testing.

Several research groups have demonstrated the advantages of having a simple and reliable POCT for INR monitoring, e.g. small sample volumes and improved turnaround time. However, POCT has limitations including preanalytical (e.g. staff competency) and biological (e.g. temperature variations, heparin contamination, extremes of haematocrit, fibrinogen levels and presence of antiphospholipid antibodies) variables. ${ }^{[13-15]}$

In $\mathrm{SA}$, the CoaguChek XS point-ofcare device could be implemented in the peripheral clinics as a screening tool for patients on long-term warfarin therapy in an attempt to reduce the workload of central anticoagulation clinics. The capacity and infrastructure of peripheral clinics would have to be assessed before installation of the devices. It is imperative that implementation of POCT be accompanied by a robust quality control system with satisfactory performance in internal and external quality assessment programmes. In specific settings, formal laboratory INR analysis will still be required when INR values $>3.6$ are obtained using this device and there is a history of bleeding events.

\section{Conclusion}

In this cohort, the CoaguChek XS provided accurate and precise INR measurements for a wide range ( $2-3.5$ units) of INR 
measurements and would be an accurate and reliable method for warfarin therapy monitoring.

Acknowledgment. We thank Dr Michelle Bronze, Dr Yuen On Wan, Dr Jenifer Vaughan and Shamima Vally for assistance with validation and statistical analysis.

\footnotetext{
References

1. Bereznicki LR, Jackson SL, Peterson GM, Jeffrey EC, Marsden KA, Jupe DM. Accuracy and clinical utility of the CoaguChek XS portable international normalised ratio monitor in a pilot study of warfarin home-monitoring. J Clin Pathol 2007;60(3):311-314. [http://dx.doi.org/10.1136/jcp.2006.037820]

2. Douketis JD, Lane A, Milne J, Ginsberg JS. Accuracy of a portable International Normalization Ratio monitor in outpatients receiving long-term oral anticoagulant therapy: Comparison with a laboratory reference standard using clinically relevant criteria for agreement. Thromb Res 1998;92(1):11-17.

3. Plesch W, Wolf T, Breitenbeck N, et al. Results of the performance verification of the CoaguChek XS system. Thromb Res 2008;123(2):381-389. [http://dx.doi.org/10.1016/j.thromres.2008.04.021]

4. Plesch W, van den Besselaar AM. Validation of the international normalized ratio (INR) in a new point-of-care system designed for home monitoring of oral anticoagulation therapy. Int J Lab Hematol 2009;31(1):20-25. [http://dx.doi.org/10.1111/j.1751-553X.2007.00998.x]

5. Sobieraj-Teague M, Daniel D, Farrelly B, Coghlan D, Gallus A. Accuracy and clinical usefulness of the CoaguChek $S$ and XS point of care devices when starting warfarin in a hospital outreach setting. Thromb Res 2009;123(6):909-913. [http://dx.doi.org/10.1016/j.thromres.2008.10.006]

6. Christensen TD, Larsen TB, Jensen C, Maegaard M, Sorensen B. International normalised ratio (INR) 6. Christensen TD, Larsen TB, Jensen C, Maegaard M, Sorensen B. International normalised ratio (INR)
measured on the CoaguChek S and XS compared with the laboratory for determination of precision measured on the CoaguChek $S$ and XS compared with the laboratory for determination of precis
and accuracy. Thromb Haemost 2009;101(3):563-569. [http://dx.doi.org/10.1160/TH08-09-0601]
}

7. Jacobson BF, Louw S, Buller H, et al. Venous thromboembolism: Prophylactic and therapeutic practice guideline. S Afr Med J 2013;103(4):261-267. [http://dx.doi.org/10.7196/SAMJ.6706]

Dalby AJ, Wessels P. Opie LH. Warfarin in non-valvular atrial fibrillation.S Afr Med J.2013:103(12):901904. [http://dx.doi.org/10.7196/samj.7172]

9. Rigelsky JM, Choe HM, Curtis DM, Brosnan MJ, Mitrovich S, Streetman DS. Accuracy of the avosure PT pro system compared with a hospital laboratory standard. Ann Pharmacother 2002;36(3):380-385. [http://dx.doi.org/10.1345/aph.1A253]

10. Hentrich DP, Fritschi J, Muller PR, Wuillemin WA. INR comparison between the CoaguChek S and a standard laboratory method among patients with self-management of oral anticoagulation. Thromb
and Res 2007;119(4):489-495. [http://dx.doi.org/10.1016/j.thromres.2006.04.003]

11. Karon BS, McBane RD, Chaudhry R, Beyer LK, Santrach PJ. Accuracy of capillary whole blood international normalized ratio on the CoaguChek S, CoaguChek XS, and i-STAT 1 point-of-care analyzers. Am J Clin Pathol 2008;130(1):88-92. [http://dx.doi.org/10.1309/DEK41W 141Y0KRN8A]

2. Ryan F, O'Shea S, Byrne S. The reliability of point-of-care prothrombin time testing: A comparison of CoaguChek S and XS INR measurements with hospital laboratory monitoring. Int J Lab Hematol 2010;32(1):e26-e33. [http://dx.doi.org/10.1111/j.1751-553X.2008.01120.x]

13. Van den Besselaar AM, Witteveen E, van der Meer FJ. Influence of haematocrit on international normalised ratio (INR) differences between a whole blood point-of-care coagulation monitor and reference prothrombin time in plasma. Thromb Haemost 2008;100(6):1181-1184

14. Phillips EM, Buchan DA, Newman N, Rajan A, Zia S. Low-molecular-weight heparin may alter pointof-care assay for international normalized ratio. Pharmacotherapy 2005;25(10):1341-1347. [http:// dx.doi.org/10.1592/phco.2005.25.10.1341]

15. Perry SL, Samsa GP, Ortel TL. Point-of-care testing of the international normalized ratio in patients with antiphospholipid antibodies. Thromb Haemost 2005;94(6):1196-1202. [http://dx.doi. org/10.1160/TH05-06-0400]

Accepted 16 November 2016 